\title{
Factors affecting calcium oxalate dihydrate fragmented calculi
} regrowth

\author{
A Costa-Bauzá, J Perelló, B Isern, P Sanchis and F Grases*
}

Address: Laboratory of Renal Lithiasis Research, University Institute of Health Sciences Research (IUNICS), University of Balearic Islands, 07122 Palma of Mallorca, Spain

Email: A Costa-Bauzá - dqufgfo@ps.uib.es; J Perelló - joan.perello@uib.es; B Isern - bernat.isern@uib.es; P Sanchis - vdqupsc4@uib.es; F Grases* - fgrases@uib.es

* Corresponding author

Published: 05 July 2006

BMC Urology 2006, 6:16 doi:10.1186/1471-2490-6-16
Received: 16 February 2006

Accepted: 05 July 2006

This article is available from: http://www.biomedcentral.com/I47/-2490/6/16

(C) 2006 Costa-Bauzá et al; licensee BioMed Central Ltd.

This is an Open Access article distributed under the terms of the Creative Commons Attribution License (http://creativecommons.org/licenses/by/2.0), which permits unrestricted use, distribution, and reproduction in any medium, provided the original work is properly cited.

\begin{abstract}
Background: The use of extracorporeal shock wave lithotripsy (ESWL) to treat calcium oxalate dihydrate (COD) renal calculi gives excellent fragmentation results. However, the retention of post-ESWL fragments within the kidney remains an important health problem. This study examined the effect of various urinary conditions and crystallization inhibitors on the regrowth of spontaneously-passed post-ESWL COD calculi fragments.
\end{abstract}

Methods: Post-ESWL COD calculi fragments were incubated in chambers containing synthetic urine varying in $\mathrm{pH}$ and calcium concentration: $\mathrm{pH}=5.5$ normocalciuria $(3.75 \mathrm{mM}), \mathrm{pH}=5.5$ hypercalciuria $(6.25 \mathrm{mM}), \mathrm{pH}=6.5$ normocalciuria $(3.75 \mathrm{mM})$ or $\mathrm{pH}=6.5$ hypercalciuria $(6.25 \mathrm{mM})$. Fragment growth was evaluated by measuring increases in weight. Fragment growth was standardized by calculating the relative mass increase.

Results: Calcium oxalate monohydrate (COM) crystals formed on COD renal calculi fragments under all conditions. Under $\mathrm{pH}=5.5$ normocalciuria conditions, only COM crystals formed (growth rate $=0.22 \pm 0.04 \mu \mathrm{g} / \mathrm{mg} \cdot \mathrm{h}$ ). Under $\mathrm{pH}=5.5$ hypercalciuria and under $\mathrm{pH}=6.5$ normocalciuria conditions, COM crystals and a small number of new COD crystals formed (growth rate $=0.32 \pm 0.03 \mu \mathrm{g} / \mathrm{mg} \cdot \mathrm{h}$ and $0.35 \pm 0.05 \mu \mathrm{g} / \mathrm{mg} \cdot \mathrm{h}$, respectively). Under $\mathrm{pH}=6.5$ hypercalciuria conditions, large amounts of COD, COM, hydroxyapatite and brushite crystals formed (growth rate $=3.87 \pm 0.34 \mu \mathrm{g} / \mathrm{mg} \cdot \mathrm{h}$ ). A study of three crystallization inhibitors demonstrated that phytate completely inhibited fragment growth $(2.27 \mu \mathrm{M}$ at $\mathrm{pH}=5.5$ and $4.55 \mu \mathrm{M}$ at $\mathrm{pH}=6.5$, both under hypercalciuria conditions), while $69.0 \mu \mathrm{M}$ pyrophosphate caused an $87 \%$ reduction in mass under $\mathrm{pH}=6.5$ hypercalciuria conditions. In contrast, $5.29 \mathrm{mM}$ citrate did not inhibit fragment mass increase under $\mathrm{pH}=6.5$ hypercalciuria conditions.

Conclusion: The growth rate of $\mathrm{COD}$ calculi fragments under $\mathrm{pH}=6.5$ hypercalciuria conditions was approximately ten times that observed under the other three conditions. This observation suggests COD calculi residual fragments in the kidneys together with hypercalciuria and high urinary $\mathrm{pH}$ values may be a risk factor for stone growth. The study also showed the effectiveness of specific crystallization inhibitors in slowing calculi fragment growth. 


\section{Background}

Calcium oxalate dihydrate renal calculi constitute the most prevalent and recurrent type of renal lithiasis $[1,2]$. They are usually associated with hypercalciuria, and on occasions with urinary $\mathrm{pH}$ values above 6.0 [3-7]. The use of extracorporeal shock wave lithotripsy (ESWL) to treat these renal calculi commonly gives excellent fragmentation results due to their fragility [8]. Nevertheless, the retention of post-ESWL fragments within the kidney is an important health problem, and a study of calcium stone patients found only $32 \%$ were stone-free 12 months after ESWL [9]. It appears that persistence and growth of fragments is common following ESWL [10-14]. In vitro [1517] and in vivo [9] studies suggest that citrate $[9,15,16]$ and phytate [17] can reduce residual post-ESWL calculi fragment growth or agglomeration. Despite those findings, however, there is a need for better understanding of the factors that contribute to stone growth following ESWL. Such knowledge will assist in designing methods for preventing such growth.

The present study belongs to a series examining the regrowth of residual post-ESWL calculi fragments in terms of calculi type, urinary conditions and presence of crystallization inhibitors. While a previous study examined regrowth of calcium oxalate monohydrate (COM) residual post-ESWL calculi fragments [17], the present study examined calcium oxalate dihydrate (COD) calculi fragments.

\section{Methods}

The study used 48 spontaneously-passed post-ESWL fragments of COD calculi collected on the day of the ESWL procedure. Fragment selection proceeded according to the general protocol applied by our laboratory in the study of all renal stones. This methodology is based on a combination of optical stereomicroscopy, infrared spectrometry and scanning electron microscopy (SEM) equipped with an energy dispersive X-ray analyzer (EDS) [18]. All selected fragments had a very similar morphology which was representative of that observed in the majority of spontaneously-passed post-ESWL COD calculi fragments. Fragment sizes varied from 2 to $4 \mathrm{~mm}$.

Fragments were not pre-treated, and were placed into four hermetic flow chambers $(3 \mathrm{~cm}$ diameter and $4 \mathrm{~cm}$ high), with each chamber containing 12 fragments. These chambers were then placed into a larger temperature-controlled $\left(37^{\circ} \mathrm{C}\right)$ chamber. Each chamber was used to test a different incubation condition: $\mathrm{pH}=5.5$ and normocalciuria ([Ca total $]=3.75 \mathrm{mM}), \mathrm{pH}=5.5$ and hypercalciuria ([Ca total $]=6.25 \mathrm{mM}), \mathrm{pH}=6.5$ and normocalciuria $([\mathrm{Ca}$ total $]=3.75 \mathrm{mM}$ ) and $\mathrm{pH}=6.5$ and hypercalciuria $([\mathrm{Ca}$ total $]=6.25 \mathrm{mM}$ ). The duration of all incubations was $192 \mathrm{~h}$, except for those under $\mathrm{pH}=6.5$ hypercalciuric con-

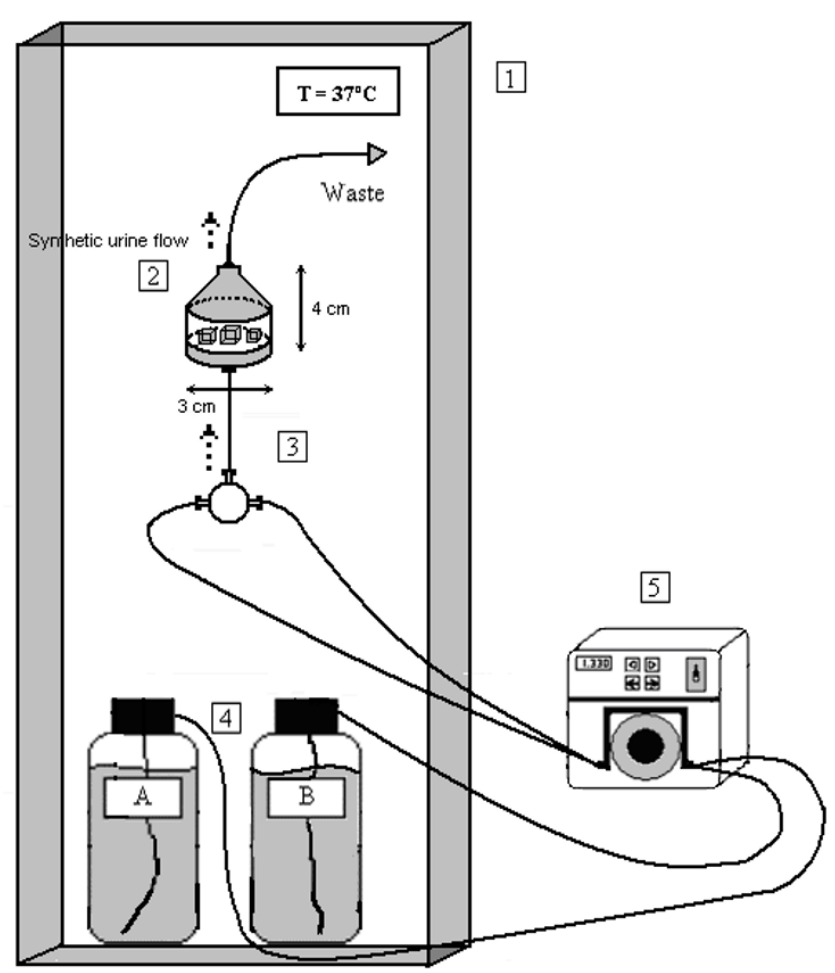

Figure I

Diagram of the experimental flow device used for COD calculi crystallization studies. I. Temperature-controlled chamber; 2. Flask containing post-ESWL calculi fragments; 3.

Three-way T mixing chamber for $A$ and $B$ solutions; 4 . $A$ and $B$ solutions for artificial urine; 5 . Peristaltic pump.

ditions, which were for $48 \mathrm{~h}$ due to the high rate of fragment mass increase. The methodology used was similar to that previously described by Chow et al. $[16,19]$. Freshly prepared synthetic urine was introduced into the flow chambers using a multichannel peristaltic pump at a rate of $750 \mathrm{~mL} /$ day through the bottom of the flasks. The calculi fragments were placed on the porous flask bottom, allowing the entire fragment surface to be exposed to the artificial urine (see Figure 1). This system allows growth of new crystals on the fragments. Fragment growth was evaluated by measuring the difference in weight between the dried fragments before and after the experiment. The weight of the fragments was measured using a precision balance after the fragments had been kept in a desiccator until their weight became constant, indicating complete dryness. The mean growth rate of the 12 fragments under each condition was calculated. The growth of the different renal calculi fragments was standardized by calculating the relative mass increase in order to avoid the effects that different surface areas may have on growth rate measurements. 
Table I: Composition of synthetic urine

\begin{tabular}{cccc}
\hline \multicolumn{2}{c}{ Solution A (mM) } & \multicolumn{2}{c}{ Solution B (mM) } \\
\hline $\mathrm{Na}_{2} \mathrm{SO}_{4} \cdot 10 \mathrm{H}_{2} \mathrm{O}$ & 19.34 & $\mathrm{NaH}_{2} \mathrm{PO}_{4} \cdot 2 \mathrm{H}_{2} \mathrm{O}$ & 15.45 \\
$\mathrm{MgSO}_{4} \cdot 7 \mathrm{H}_{2} \mathrm{O}$ & 5.93 & $\mathrm{Na}_{2} \mathrm{HPO}_{4} \cdot 12 \mathrm{H}_{2} \mathrm{O}$ & 15.64 \\
$\mathrm{NH}_{4} \mathrm{Cl}$ & 86.73 & $\mathrm{NaCl}_{2}$ & 223.08 \\
$\mathrm{KCl}$ & 162.60 & $\mathrm{Na}_{2} \mathrm{C}_{2} \mathrm{O}_{4}$ & 0.57 \\
\hline
\end{tabular}

Various volumes of a I M calcium solution (prepared by dissolving calcium carbonate with hydrochloric acid) were added to solution $A$ to obtain final calcium concentrations ranging from $3.75-6.25 \mathrm{mM}$.

The effects of the crystallization inhibitors phytate, pyrophosphate and citrate were evaluated. The concentrations used corresponded to the physiological concentrations in urine.

The experimental research has been performed with the approval of the Bioethics Committee of the University of Balearic Islands and the research was carried out in compliance with the Helsinki Declaration.

\section{Synthetic urine}

Synthetic urine supersaturated with calcium oxalate was prepared using a three-way $\mathrm{T}$ mixing chamber containing equal volumes of solutions $\mathrm{A}$ and $\mathrm{B}$ (compositions shown in Table 1). The $\mathrm{pH}$ of both solutions was adjusted either to 5.5 or 6.5. Solutions were stored for a maximum of 1 week at $4{ }^{\circ} \mathrm{C}$. Chemicals of reagent-grade purity were dissolved in deionized and redistilled water. All solutions were filtered through a $0.45 \mu \mathrm{m}$ pore filter before use.

\section{Effect of crystal inhibitors}

Compounds reported to inhibit crystal formation were added to the synthetic urine to the following final concentrations: $1.32-5.29 \mathrm{mM}$ citrate as a sodium salt (supplied by Probus), $0.15-4.55 \mu \mathrm{M}$ phytate as a sodium salt (supplied by Sigma), and 11.5-69.0 $\mu \mathrm{M}$ pyrophosphate as a sodium salt (supplied by Merck).

\section{Calcium-citrate complexation}

Owing to the high concentration of citrate used, and considering its ability to complex with calcium ions, a calcium supplement was used in experiments involving citrate ions in order to achieve the same calcium oxalate supersaturation value as occurs in the absence of citrate. It must be noted that a decrease in supersaturation would imply a decrease in the crystallization rate that could not be assigned to inhibitory effects. The amount of calcium ions added was potentiometrically calculated using a calcium-selective electrode (Ingold) and a potentiometer (Crison 2002). Calcium standards in the presence and absence of citrate were prepared using synthetic urine as a matrix. The activity of free calcium ions must be the same in the presence and absence of citrate. Therefore, the calcium concentration was increased by $0.15 \mathrm{mM}$ per 0.53

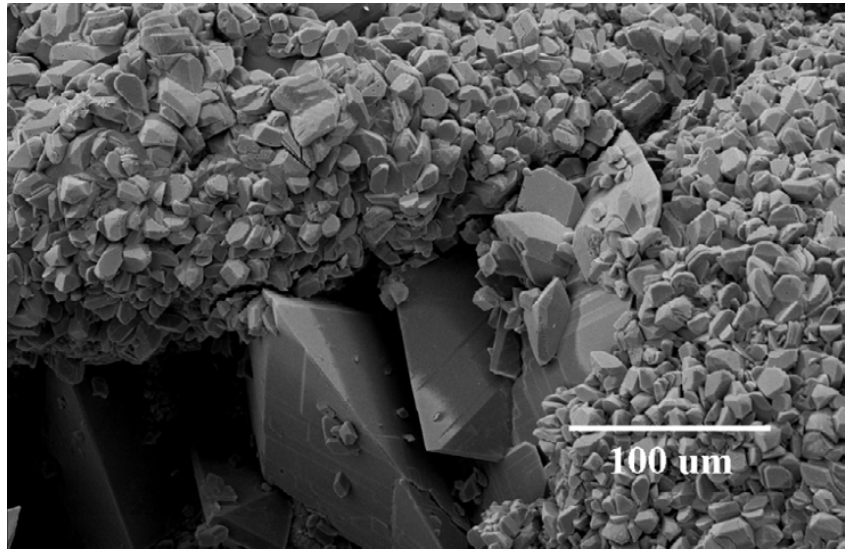

Figure 2

COM crystal formation on a post-ESWL COD renal calculus fragment following a $192 \mathrm{~h}$ incubation in normocalciuric (3.75 $\mathrm{mM})$ and normooxaluric $(0.28 \mathrm{mM})$ synthetic urine $(\mathrm{pH}=$ 5.5).

$\mathrm{mM}$ increase in the citrate concentration. The levels of phytate and pyrophosphate used were so low that the decrease in free calcium concentration was negligible, as determined potentiometrically. Consequently, it was not necessary to add a calcium supplement to the solutions containing phytate and pyrophosphate.

\section{Results}

Under all four incubation conditions, COM crystals were found to form on COD calculi fragments (Figures 2, 3, 4, $5)$. New COD crystal formation represented the minority (less than $50 \%$ ) of crystal formation under $\mathrm{pH}=5.5$ hypercalciuric (Figure 3 ) and $\mathrm{pH}=6.5$ normocalciuric

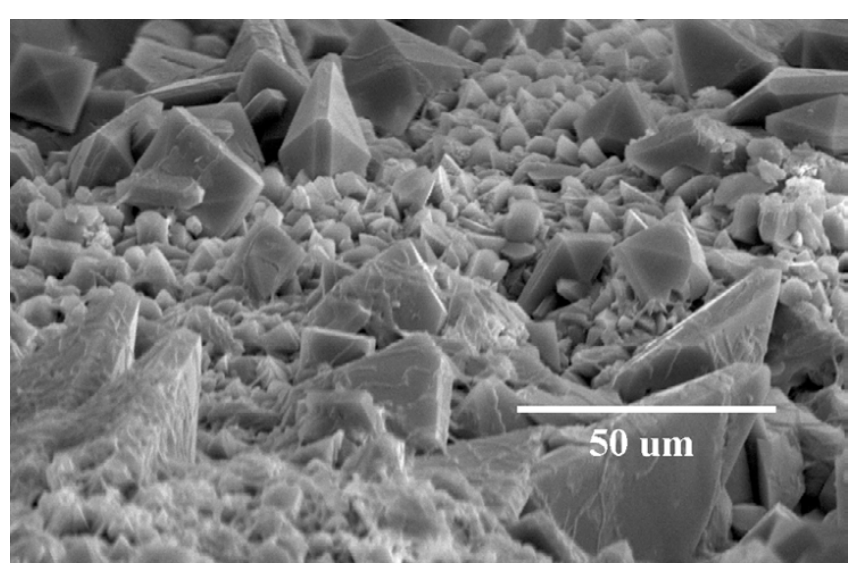

Figure 3

COM and COD crystal formation on post-ESWL COD renal calculi fragments following a $192 \mathrm{~h}$ incubation in hypercalciuric $(6.25 \mathrm{mM})$ and normooxaluric $(0.28 \mathrm{mM})$ synthetic urine $(\mathrm{pH}=5.5)$. 


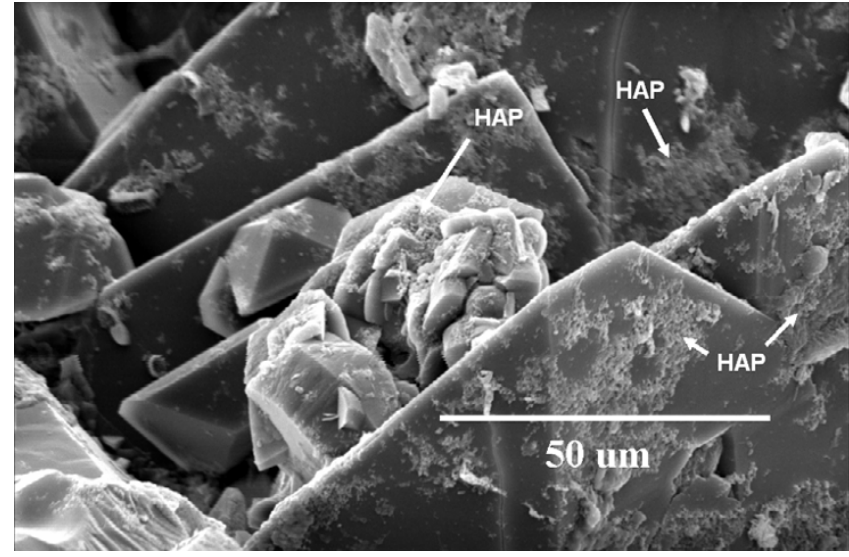

Figure 4

COM, COD and HAP crystal formation (arrows) on postESWL COD renal calculi fragments following a $192 \mathrm{~h}$ incubation in normocalciuric $(3.75 \mathrm{mM})$ and normooxaluric $(0.28$ $\mathrm{mM})$ synthetic urine $(\mathrm{pH}=6.5)$.

(Figure 4) conditions. In contrast, large amounts of COD crystals formed under $\mathrm{pH}=6.5$ hypercalciuric conditions (Fig 5a,c). Significant amounts of hydroxyapatite (HAP) and brushite (BRU) crystals formed under $\mathrm{pH}=6.5$ hypercalciuria conditions (Figure 5a,b), but not under other conditions.

The mean growth rates of COD calculi fragments under the four incubation conditions are summarized in Table 2 . While growth rates of $0.22-0.35 \mu \mathrm{g} / \mathrm{mg} \cdot \mathrm{h}$ were observed under the majority of conditions, the rate was approximately ten times greater $(3.87 \pm 0.43 \mu \mathrm{g} / \mathrm{mg} \cdot \mathrm{h})$ under $\mathrm{pH}=6.5$ hypercalciuria conditions.

The effects of three known crystallization inhibitors (phytate, pyrophosphate and citrate) were investigated (Figures 6 and 7). We found that addition of $2.27 \mu \mathrm{M}$ phytate to the $\mathrm{pH}=5.5$ hypercalciuria incubation, and the addition of $4.55 \mu \mathrm{M}$ phytate to the $\mathrm{pH}=6.5$ hypercalciuria incubation completely inhibited the COD calculi fragment mass increase. Addition of lower phytate concentrations (less than $2.27 \mu \mathrm{M}$ ), mainly inhibited COM crystal formation. The addition of $69.0 \mu \mathrm{M}$ pyrophosphate to the $\mathrm{pH}=6.5$ hypercalciuria incubation resulted in an $87 \%$ reduction of calculi fragment mass increase. The addition of $5.29 \mathrm{mM}$ citrate to the $\mathrm{pH}=6.5$ hypercalciuria incubation had no effect on the COD calculi fragment mass increase.

\section{Discussion}

The present study found that in normocalciuric/normooxaluric urine at $\mathrm{pH}=5.5$, only new COM crystals formed on COD calculi fragments. At the same $\mathrm{pH}$, new COD crystals only formed under hypercalciuric condi-

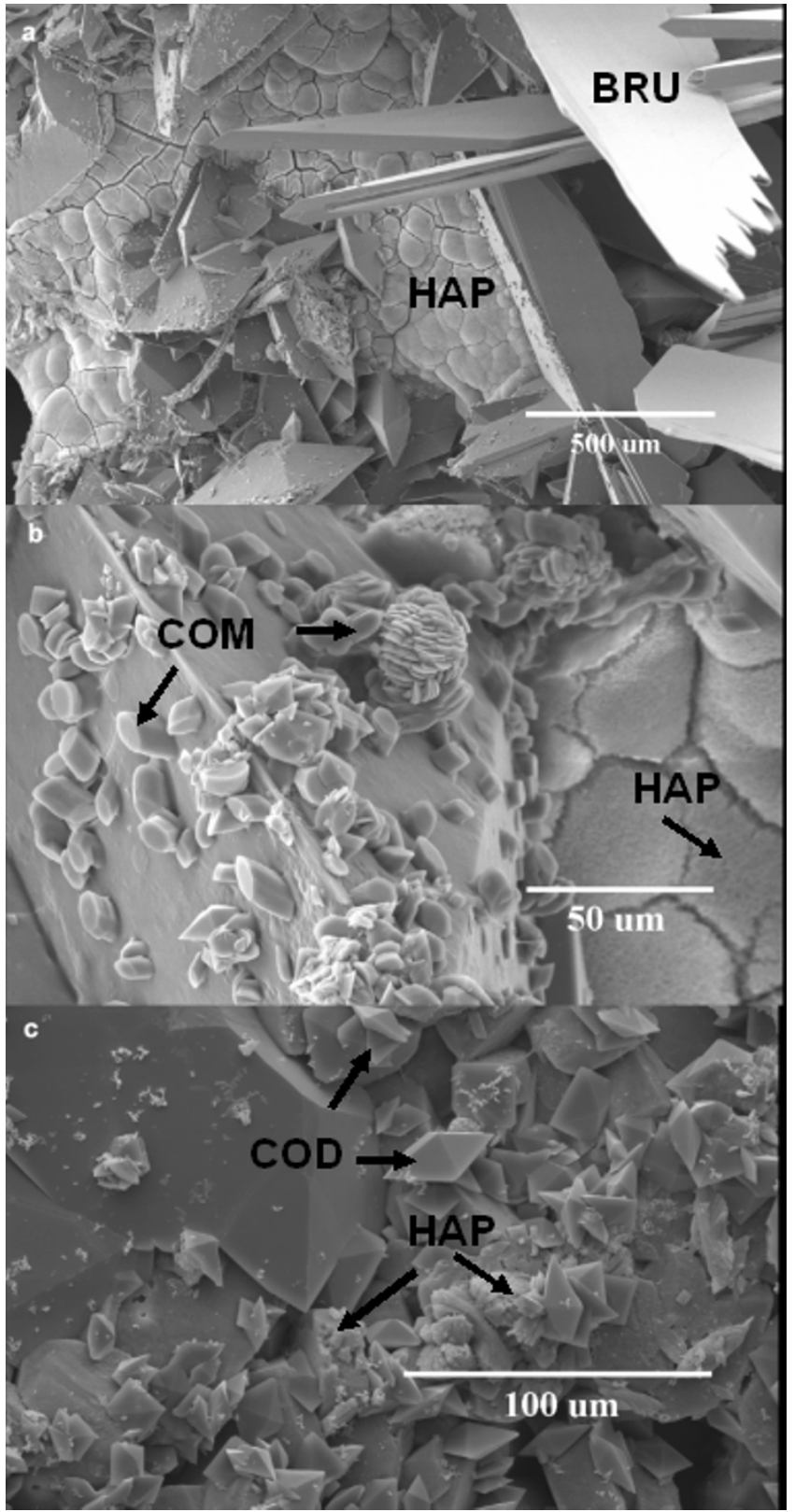

Figure 5

a) HAP and BRU crystal, b) COM and HAP crystal and c) COD and HAP crystal formation on post-ESWL COD renal calculi fragments following a $48 \mathrm{~h}$ incubation in hypercalciuric $(6.25 \mathrm{mM})$ and normooxaluric $(0.28 \mathrm{mM})$ synthetic urine $(\mathrm{pH}$ $=6.5$ ).

tions, in addition to COM crystals (Figure 3). Low phytate concentrations (less than $2.27 \mu \mathrm{M}$ ), inhibited this COM crystal formation. At $\mathrm{pH}=6.5$, COD crystals formed under normocalciuric conditions (Figure 4), while under hypercalciuria conditions the calcium phosphates HAP and BRU also formed with the COD crystals. These findings are consistent with several clinical observations 


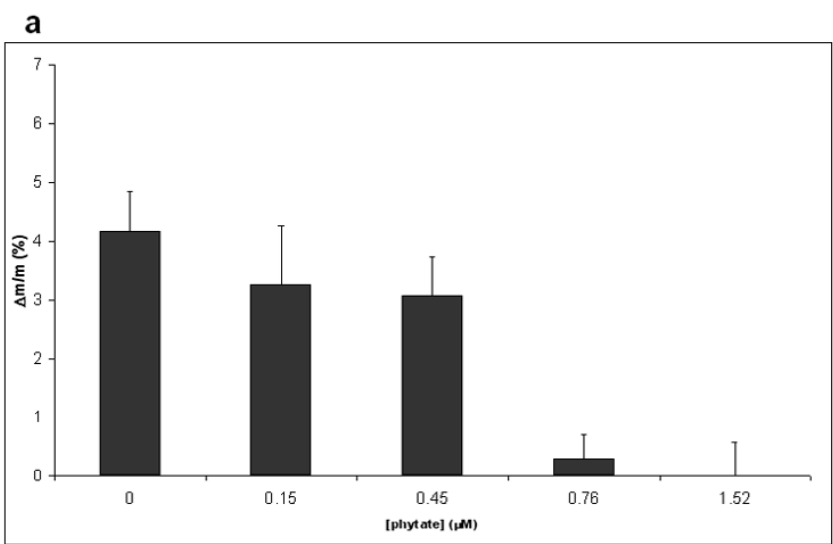

b

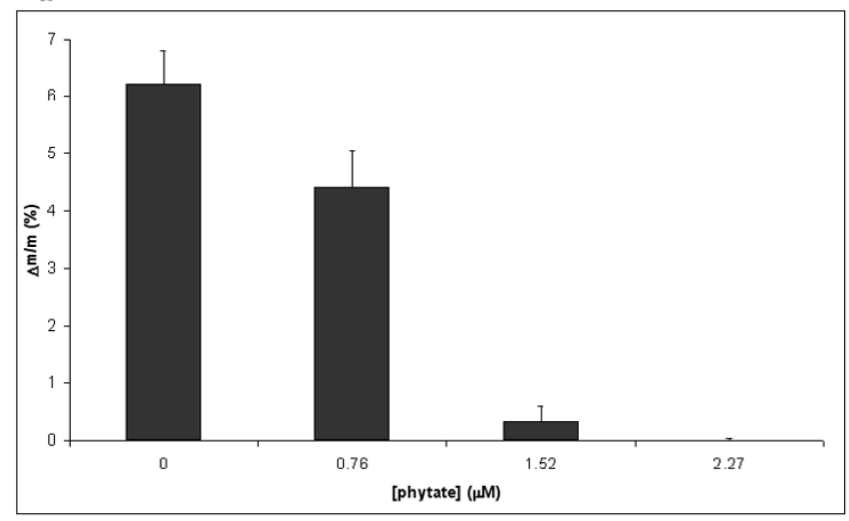

Figure 6

Increase in the relative weight of post-ESWL COD renal calculi fragments incubated for $196 \mathrm{~h}$ in normooxaluric $(0.28$ $\mathrm{mM}$ ) synthetic urine at $\mathrm{pH}=5.5$ in the absence or presence of phytate. Values represent mean \pm SEM for 12 fragments. $a$. Normocalciuric urine $([\mathrm{Ca}$ total $]=3.75 \mathrm{mM})$. b. Hypercalciuric urine $([\mathrm{Ca}$ total $]=6.25 \mathrm{mM})$.

showing that COM calculi are generally associated with a lack of crystallization inhibitors and COD calculi with hypercalciuria and high urinary $\mathrm{pH}$ values [3-6]. It is important to emphasize that the growth rate of COD calculi fragments was similar under all conditions except under $\mathrm{pH}=6.5$ hypercalciuria, conditions under which the growth rate was approximately ten times that observed under other conditions (see Table 2). These findings suggest that the presence of COD calculi fragments in the kidneys together with hypercalciuria and high urinary $\mathrm{pH}$ values (around 6.5) are a high risk factor for stone development. These data suggest that a COD calculus fragment of only $5 \mathrm{mg}$ could become a $45 \mathrm{mg}$ fragment in just 3 months under these conditions.

Crystallization inhibitors can notably retard calculi fragment development. The present study found that phytate at concentrations found in normal human urine [20] totally prevented COD calculi fragment growth. In addi-
Table 2: Mean growth rates (relative mass increase, $\mu \mathrm{g} / \mathrm{mg} \cdot \mathrm{h}$ ) of post-ESWL COD renal calculi fragments under different incubation conditions. All incubations contained $0.28 \mathrm{mM}$ oxalate. Results are expressed as mean $\pm \operatorname{SEM}(n=12)$.

\begin{tabular}{cccc}
\hline \multicolumn{2}{c}{$\mathbf{p H}=\mathbf{5 . 5}$} & \multicolumn{2}{c}{$\mathbf{p H = 6 . 5}$} \\
\hline$[$ Ca total] $=$ & {$[$ Ca total] $=$} & {$[$ Ca total] $=$} & {$[$ Ca total] $=$} \\
$3.75 \mathrm{mM}$ & $6.25 \mathrm{mM}$ & $3.75 \mathrm{mM}$ & $6.25 \mathrm{mM}$ \\
$0.22 \pm 0.04 *$ & $0.32 \pm 0.03 *$ & $0.35 \pm 0.05 *$ & $3.87 \pm 0.43$ \\
\hline
\end{tabular}

$* p<0.05$ vs. $\mathrm{pH}=6.5$ and $[\mathrm{Ca}$ total $]=6.25 \mathrm{mM}$ conditions.

No significant differences were found between other groups

tion, pyrophosphate also reduced the COD calculi fragment mass increase. In contrast, citrate did not show any significant crystallization inhibitory capacity under the conditions investigated. This finding appears to be in disagreement with previous reports showing that high citrate concentrations reduced the growth rate of stones by more than 50\% [16]. However, this apparent discordance may be because the stated growth rate reduction must be assigned to citrate complexation with calcium, which results in an important reduction in the relative calcium oxalate supersaturation. Thus, it must be considered that in the present study a calcium supplement was added to obtain the same calcium oxalate supersaturation value found in the absence of citrate. Interestingly, while citrate did not inhibit calcium salt crystallization on COD crystals in the present study, it was shown to inhibit calcium salt crystallization on glycoproteins and organic matter $[21,22]$. These observations again highlight the specificity of crystallization inhibitors.

\section{Conclusion}

The growth rate of COD calculi fragments under $\mathrm{pH}=6.5$ hypercalciuria conditions was approximately ten times that observed under other conditions. This observation suggests COD calculi residual fragments in the kidneys together with hypercalciuria and high urinary $\mathrm{pH}$ values may represent an important risk factor for stone development. In addition, the study found that specific crystallization inhibitors can effectively reduce calculi fragment growth.

\section{Competing interests}

The author(s) declare that they have no competing interests.

\section{Authors' contributions}

AC conceived the study and participated in the search and selection of COD calculi fragments. JP performed the crystallization studies under hypercalciuria conditions. BI performed the crystallization studies under normocalciuria conditions and $\mathrm{pH}=5.5$. PS performed the crystallization studies under normocalciuria conditions and $\mathrm{pH}=6.5$. FG participated in the study design and coordination, and 
a

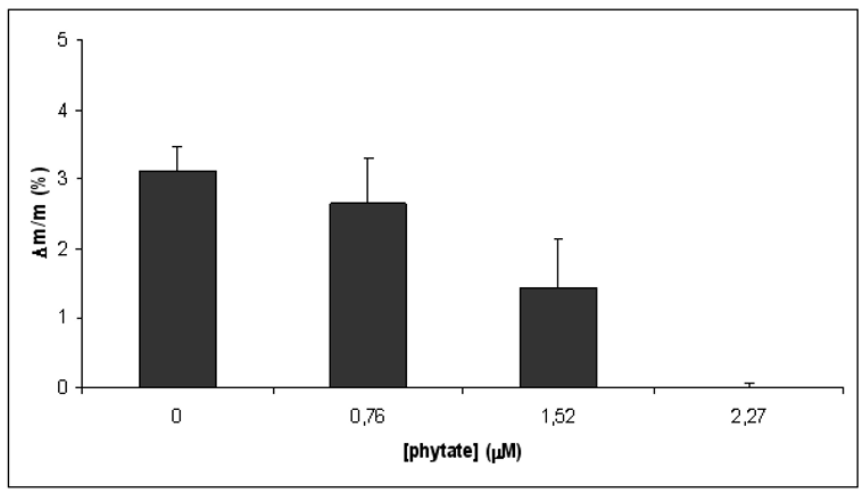

C

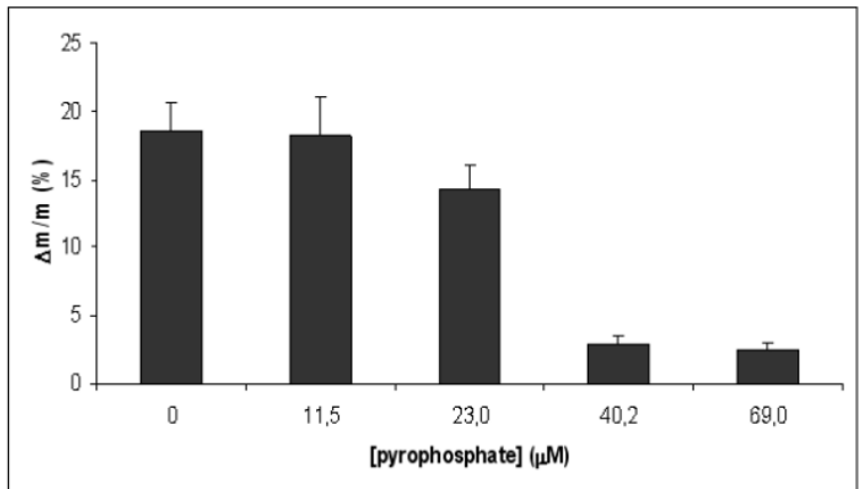

b

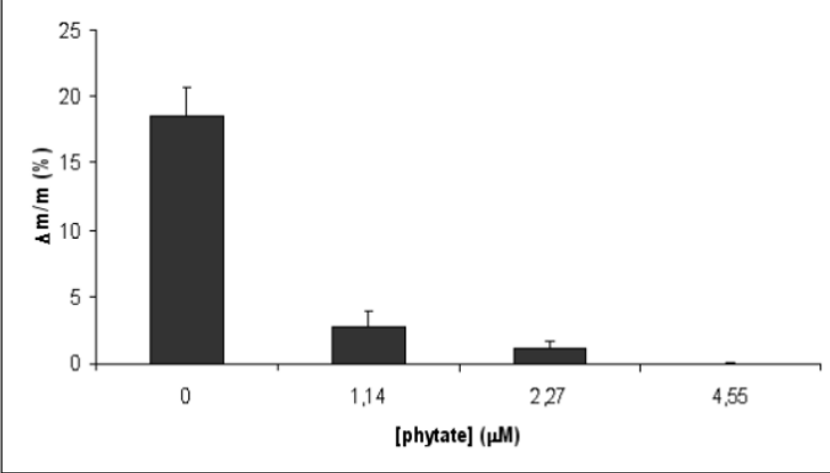

d

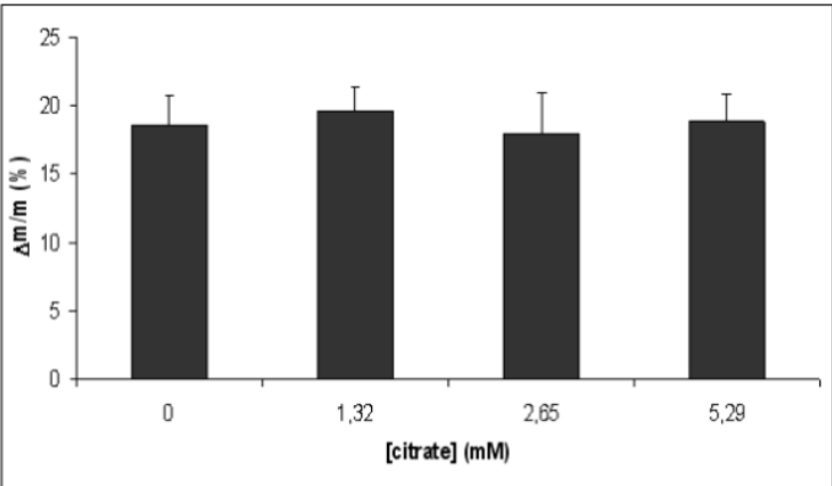

\section{Figure 7}

Increase in the relative weight of post-ESWL COD renal calculi fragments following incubation in normooxaluric $(0.28 \mathrm{mM})$ synthetic urine at $\mathrm{pH}=6.5$. Values represent the mean \pm SEM for 12 fragments. a. Incubation in normocalciuric urine ([Ca total $]=3.75 \mathrm{mM}$ ) for 192 hours in the absence or presence of phytate. $\mathbf{b}$. Incubation in hypercalciuric urine ([Ca total] $=6.25$ $\mathrm{mM})$ for 48 hours in the absence or presence of phytate. c. Incubation in hypercalciuric urine ([Ca total] $=6.25 \mathrm{mM})$ for 48 hours in the absence or presence of pyrophosphate. $d$. Incubation in hypercalciuric urine $([\mathrm{Ca}$ total $]=6.25 \mathrm{mM})$ for 48 hours in the absence or presence of citrate.

assisted in preparation of the manuscript. All authors read and approved the final manuscript.

\section{Acknowledgements}

P.S. is grateful to the Spanish Ministry of Education, Culture and Sport for an FPU program fellowship. B.I. is grateful to the Conselleria d'Innovació $i$ Energia del Govern de les Illes Balears for a fellowship. Financial support from the Conselleria d'Innovació i Energia, Govern Balear (Grant PROIB2002GCI-04) and from the Spanish Ministry of Science and Technology (project BQU 2003-01659) is gratefully acknowledged.

\section{References}

I. Krepinsky J, Ingram AJ, Churchill DN: Metabolic investigation of recurrent nephrolithiasis: compliance with recommendations. Urology 2000, 56:915-920.

2. Grases F, Costa-Bauzá A, Ramis M, Montesinos V, Conte A: Recurrence of renal lithiasis. Scand J Urol Nephrol 2003, 37:482-486.

3. Daudon M, Reveillaud RJ: Whewellite and weddellite: toward a different etiopathogenesis. The significance of morphological typing of calculi. Nephrologie 1984, 5: 195-201.
4. Galan JA, Conte A, Llobera A, Costa-Bauzá A, Grases F: A comparative study between etiological factors of calcium oxalate monohydrate and calcium oxalate dihydrate urolithiasis. Urol Int 1996, 56:79-85.

5. Asplin JR, Lingeman J, Kahnoski R, Mardis H, Parks JH, Coe FL: Metabolic urinary correlates of calcium oxalate dihydrate in renal stones. J Urol 1998, 159:664-668.

6. Parent X, Boess G, Brignon P: Calcium oxalate lithiasis. Relationship between biochemical risk factors and crystalline phase of the stone. Prog Urol 1999, 9:105I-1056.

7. Grases F, Costa-Bauzá A, Ramis M, Monstesinos V, Conte A: Simple classification of renal calculi closely related to their micromorphology and etiology. Clin Chim Acta 2002, 22:29-36.

8. Cecchetti W, Tasca A, Zattoni F, Villi G, Levorato CA, Pagano F: Five years experience in experimental laser lithotripsy. Eur Urol 1993, 24:185-189.

9. Cicerello E, Merlo F, Gambaro G, Maccatrozzo L, Fandella A, Baggio $B$, Anselmo G: Effect of alkaline citrate therapy on clearance of residual renal stone fragments after extracorporeal shock wave lithotripsy in sterile calcium and infection nephrolithiasis patients. J Urol 1994, I $51: 5-9$.

10. Delvecchio FC, Preminger GM: Management of residual stones. Urol Clin North Am 2000, 27:347-354. 
11. Zanetti G, Montanari E, Mandressi A, Guarneri A, Ceresoli A, Mazza L, Trinchieri , Pisani E, Mazza L: Long-term results of extracorporeal shockwave lithotripsy in renal stone treatment. J Endourol 1988, 2:163-I7|.

12. Zanetti G, Seveso M, Montanari E, Guarneri A, Del Nero A, Nespoli $R$, Trinchieri A: Renal stone fragments following shock wave lithotripsy. J Urol 1997, I 58:352-355.

13. Yu CC, Lee YH, Huang JK, Chen MT, Chen KK, Lin AT, Chang LS: Long-term stone regrowth and recurrence rates after extracorporeal shock wave lithotripsy. $\mathrm{Br} J$ Urol I993, 72:688-69I.

14. Carr LK, D'A Honey J, Jewett MA, Ibanez D, Ryan M, Bombardier C: New stone formation: a comparison of extracorporeal shock wave lithotripsy and percutaneous nephrolithotomy. J Urol 1996, 155:1565-1567.

15. Suzuki K, Tsugawa R, Ryall RL: Inhibition by sodium-potassium citrate (CG- I20) of calcium oxalate crystal growth on to kidney stone fragments obtained from extracorporeal shock wave lithotripsy. $\mathrm{Br}$ J Urol 1991, 68: I32-137.

16. Chow K, Dixon J, Gilpin S, Kavanagh JP, Rao PN: Citrate inhibits growth of residual fragments in an in vitro model of calcium oxalate renal stones. Kidney Int 2004, 65: I724- 1730.

17. Costa-Bauzá A, Perelló J, Isern B, Grases F: An experimental study on residual lithiasis after shock wave lithotripsy. Urol Res 2005, 33:5I-56.

18. Grases F, Garcia-Ferragut L, Costa-Bauzá A: Analytical study of renal calculi. A new insight. Recent Res Devel in Pure \& Applied Anal Chem 1998, I:187-206.

19. Chow K, Dixon J, Gilpin S, Kavanagh JP, Rao PN: A stone farm: development of a method for simultaneous production of multiple calcium oxalate stones in vitro. Urol Res 2004, 32:55-60.

20. Grases F, Simonet BM, Vucenik I, Prieto RM, Costa-Bauzá A, March JG, Shamsuddin AM: Absorption and excretion of orally administered inositol hexaphosphate (IP(6) or phytate) in humans. BioFactors 200I, I5:53-6I.

21. Grases F, Isern B, Perelló J, Costa-Bauzá A: The role of glycoproteins in calcium oxalate crystal development. BJU Int 2004 94:|77-|8I.

22. Grases F, Isern B, Perelló J, Costa-Bauzá A: Role of the organic matter in calcium oxalate lithiasis. Front Biosci 2005, 10:1534-1538.

\section{Pre-publication history}

The pre-publication history for this paper can be accessed here:

http://www.biomedcentral.com/1471-2490/6/16/prepub

\section{Publish with Biomed Central and every scientist can read your work free of charge}

"BioMed Central will be the most significant development for disseminating the results of biomedical research in our lifetime. "

Sir Paul Nurse, Cancer Research UK

Your research papers will be:

- available free of charge to the entire biomedical community

- peer reviewed and published immediately upon acceptance

- cited in PubMed and archived on PubMed Central

- yours - you keep the copyright 